\title{
Regional Anesthesia and Pain
}

\section{The radial nerve should be blocked before the ulnar nerve during a brachial plexus block at the humeral canal}

\author{
[Le nerf radial doit être anesthésié avant le nerf cubital pendant un blocage du \\ plexus brachial au travers du canal huméral]
}

Emmanuel Guntz MD, ${ }^{*}$ Pierre Herman MD, ${ }^{*}$ Alain Delbos MD, $†$ Maurice Sosnowski MD PhD*

Purpose: The brachial plexus block through the humeral canal as described by Dupré is indicated in hand and forearm surgery. This block requires a multi-stimulation technique that emphasizes the necessity of a rigorous and safe technique. Nerve injury associated with regional anesthesia can entail significant morbidity for patients. Thus, we investigated the brachial block sequence in terms of unintended nerve stimulation as a surrogate of potential nerve injury.

Methods: Sixty patients were randomly allocated in two groups of 30. In Group I the radial nerve was blocked before the ulnar nerve. In Group II the ulnar nerve was blocked before the radial nerve. During the radial nerve approach we recorded, if present, an ulnar nerve response. During the ulnar nerve approach we recorded, if present, a radial nerve response.

Results: In Group I while looking for the radial nerve, in 50\% of the cases, an ulnar motor response was recorded. In Group II while looking for the ulnar nerve, a radial motor response was recorded in 10\% of the cases.

Conclusion: Our results indicate that the radial nerve should be blocked before the ulnar nerve when performing a brachial plexus block at the humeral canal.

Objectif: Le blocage du plexus brachial au niveau du canal huméral, selon la technique de Dupré, est indiqué pour des opérations à la main et à l'avant-bras. Ce bloc nécessite une multi-stimulation, technique qui doit être faite avec rigueur et en toute sécurité. La lésion d'un nerf associée à l'anesthésie régionale peut donner lieu à une morbidité importante. La séquence du bloc brachial a donc été examinée sous l'angle de la stimulation involontaire d'un nerf, incident porteur d'une lésion potentielle à ce nerf.

Méthode : Soixante patients ont été répartis aléatoirement en deux groupes de 30. Dans le groupe I, le nerf radial a été bloqué avant le nerf cubital. Dans le groupe II, nous avons fait l'inverse. Pendant l'approche du nerf radial, nous avons noté la présence ou non d'une réponse du nerf cubital. Pendant l'approche du nerf cubital, nous avons noté la réponse du nerf radial selon le cas.

Résultats : Dans le groupe I, pendant le blocage du nerf radial, nous avons noté une réponse motrice cubitale dans 50 \% des cas. Dans le groupe II, pendant le blocage du nerf cubital, nous avons noté une réponse motrice radiale dans $10 \%$ des cas.

Conclusion : Nos résultats indiquent que le nerf radial doit être bloqué avant le nerf cubital quand nous réalisons un bloc du plexus brachial au niveau du canal huméral.

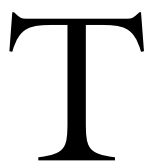

HE humeral approach to the brachial plexus has been proposed recently by Dupré. ${ }^{1}$ The four branches of the plexus are blocked at the junction of the proximal and middle thirds of the arm. At this level they are separated from each other and can be blocked one by one. The humeral approach provides a greater success rate compared to the axillary approach. ${ }^{2}$ Moreover, the minimum stimulation threshold for predictable results has been defined for the humeral route. $^{3}$

From the Department of Anesthesiology, Université Libre de Bruxelles, Hôpital Universitaire Saint-Pierre, * Brussels, Belgium; and Clinique des Cêdres, $†$ Toulouse, France.

Address correspondence to: Dr. Emmanuel Guntz, Department of Anesthesiology, C.H.U. Saint-Pierre, rue Haute, 322, Brussels 1000,

Belgium. Phone : 003225353593; Fax: 003225354070; E-mail: eguntz@ulb.ac.be

Accepted for publication August 26, 2003.

Revision accepted January 13, 2004. 
Despite these benefits the technique can still expose the nerves to injuries.

Considering the onset times of the four nerve blocks, Gaertner confirmed Dupré's initial nerve blocking sequence (median, ulnar, radial and musculocutaneous nerves). ${ }^{4}$

On the basis of classical anatomical descriptions, we thought that the superficial ulnar nerve, if already blocked, could be exposed to nerve injury during localization of the deep radial nerve. Therefore we conducted this prospective, randomized study and compared two sequences: median, radial, ulnar, and musculocutaneous nerves $v s$ median, ulnar, radial and musculocutaneous nerves in terms of ulnar nerve stimulation during the radial nerve localization and conversely.

\section{Methods}

The Medical Ethics Committee approved this prospective study and written informed consent was obtained for each patient.

We defined two groups. In Group I the nerve blocking sequence was median, radial, ulnar, and musculocutaneous nerve. In Group II the nerve blocking sequence was median, ulnar, radial, and musculocutaneous nerve. In Group I during the radial nerve approach we recorded, if present, an ulnar nerve response. In Group II during the ulnar nerve approach we recorded, if present, a radial nerve response.

We calculated sample size based on our initial results in two groups of ten patients. Results of the entire study, expressed as ratios, were analyzed with Fisher's exact test. $P<0.05$ was considered significant. Analyses were performed with the Statxact 5 Software (Cytel Software Corporation, Cambridge, MA, USA).

The patients, ASA physical status I to III without preexisting neurological illness, undergoing selective forearm and hand surgery were randomly allocated to one group and one of the two first authors (experienced anesthesiologists). We performed these randomizations with the random permuted blocks methods. ${ }^{5}$

Patients were monitored, (pulse oximeter oxygen saturation, non-invasive brachial pressure, electrocardiogram), a 20 -gauge $i v$ line was established and sedation was provided with 1 or $2 \mathrm{mg}$ of midazolam.

The needle puncture site is located at the junction of the proximal and middle thirds of the arm at the level of the brachial artery (Figure). For the median nerve, the needle is inserted tangentially to the skin. The expected motor response is a flexion of the wrist and the second and third fingers, associated with a contraction of the palmaris longus muscle. For the ulnar nerve, the needle is redirected downward, the
TABLE Incidence of ulnar and radial nerve stimulation during localization of the radial and ulnar nerve, respectively

\begin{tabular}{ll}
\hline & $\begin{array}{l}\text { Ulnar nerve stimulation during radial } \\
\text { nerve approach } \\
\text { Group I }\end{array}$ \\
Anesthesiologist 1 & $7 / 30^{*}$ \\
Anesthesiologist 2 & $8 / 15$ \\
& Radial nerve stimulation during ulnar \\
& nerve approach \\
Group II & $3 / 30$ \\
Anesthesiologist 1 & $2 / 15$ \\
Anesthesiologist 2 & $1 / 15$ \\
\hline
\end{tabular}

*Significant difference $P=0.0015$ Group I vs Group II.

expected motor response is a flexion and ulnar inclination of the wrist and a flexion of the fourth and fifth fingers. For the radial nerve the needle is withdrawn nearly completely and redirected perpendicularly to the skin. The expected motor response is an extension of the wrist and fingers. For the musculocutaneous nerve, the biceps brachialis muscle is lifted up; the needle is inserted under the muscle, over the brachial artery and the median nerve. The expected motor response is a flexion of the forearm on the arm.

A 22-gauge insulated $50-\mathrm{mm}$ needle (Stimuplex A Braun, Melsungen, Germany) is used. The nerve stimulator (Stimuplex HNS 11, Braun, Melsungen, Germany) is set at $1.5 \mathrm{~mA}, 2 \mathrm{~Hz}, 0.1 \mathrm{msec}$. When motor responses are obtained, the nerve stimulation is progressively decreased to $0.5 \mathrm{~mA}$. After careful aspiration and a $1-\mathrm{mL}$ test dose, the local anesthetic $(8$ $\mathrm{mL}$ of lidocaine $1.5 \%$ with epinephrine $1: 200,000$ ) is injected at each site except on the musculocutaneous nerve $(5 \mathrm{~mL})$.

\section{Results}

During the preliminary study we recorded five ulnar nerve responses in Group I and one radial nerve response in Group II. Fisher's exact test was non significant $(P=0.141)$ and power was .29. Taking into account these calculations, we needed two groups of 23 patients to obtain a power of $80 \%$. We decided to incorporate 60 patients in two groups of 30 (power $=.91$ ).

The mean age, weight and height of the 60 patients was $33 \mathrm{yr}$ (range 18-65 yr), 71 kg (range 52-95 kg) and $172 \mathrm{~cm}$ (range 157-185 cm). Only two blocks had to be completed at the elbow (one radial nerve and one median nerve).

In Group I, while attempting to localize the radial nerve, 15 ulnar motor responses were recorded. In Group II, while attempting to localize the ulnar nerve, three radial motor responses were recorded. 


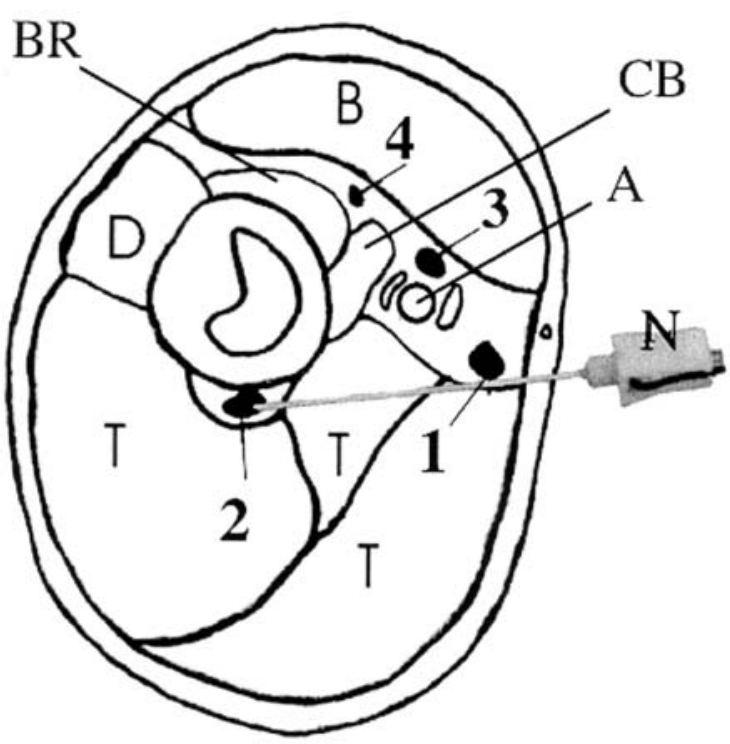

FIGURE Transverse section of the upper limb at the humeral canal level

$\mathrm{A}=$ brachial artery $\mathrm{B}=$ biceps brachialis muscle; $\mathrm{BR}=$ brachialis muscle $; \mathrm{CB}=$ coracobrachialis muscle $; \mathrm{D}=$ deltoid muscle $; \mathrm{T}=$ triceps muscle; $1=$ ulnar nerve; $2=$ radial nerve; 3 = median nerve; 4 = musculocutaneous nerve; $\mathrm{N}=$ neurostimulation needle.

Considering the frequency of motor responses recorded on one nerve (radial or ulnar) while the anesthesiologist was attempting to localize the other (ulnar or radial), the difference between the two groups is significant $(P=0.0015)$. Unintended nerve stimulation was similar for the two anesthesiologists (Table).

\section{Discussion}

During the radial nerve block, as described by Dupré, the needle, inserted perpendicular to the skin, is in the same plane as the ulnar and radial nerves (Figure). Thus, the ulnar nerve may be stimulated during the radial nerve approach; conversely, the radial nerve can also be stimulated during the ulnar nerve approach. The situation is different for the two other nerves. The median nerve (already located) is positioned above the humeral artery. During localization of the musculocutaneous nerve the biceps brachialis muscle is lifted up, allowing the needle to be introduced over the plane of the median nerve.

Our results show that the ulnar nerve is stimulated in half of the radial blocks, while the radial nerve is stimulated in only one out of ten blocks in the inverse sequence. Consequently, if the ulnar nerve is already blocked, it might, theoretically, be injured in $50 \%$ of cases during localization of the radial nerve as opposed to a five times lesser occurrence of radial nerve injury during ulnar nerve localization.

The frequency of unintended nerve stimulation must be related to the time required to complete the procedure and to the onset time of sensory block. In that respect the large study by Carles ( 1,417 patients) is of major interest. ${ }^{3}$ The author showed that, using Dupré's technique, $10 \pm 5 \mathrm{~min}$ are necessary to perform the block. The sensory block onset time is $10 \pm$ $2 \mathrm{~min}$ for the ulnar nerve and $13 \pm 5 \mathrm{~min}$ for the radial nerve. Thus, knowing that a sensory ulnar nerve block can be achieved in eight minutes and that completion of the entire humeral block may need $15 \mathrm{~min}$, it is obvious that deep nerves should be blocked before superficial ones.

The incidence of peripheral neuropathies for the brachial plexus block through the humeral canal is very low (range: $0-6.8 \%)^{3,4,6,7}$ In France, the number of regional anesthetic procedures has increased 14fold between 1980 and $1996 .{ }^{8}$ Because of this recent large increase it is mandatory to remain cautious when interpreting good results concerning the safety of the brachial plexus block through the humeral canal.

After a nerve block, the occurrence of neuropathy can either be immediate or delayed. The mechanism has not been elucidated. Moreover, we cannot rely on paresthesia to predict nerve injury. ${ }^{9}, 10$ Constant evolution of the number of procedures and unknown mechanisms underline the importance of a rigorous block sequence, particularly during a multi-stimulation technique. This is emphasized by the poor outcome of chronic neurological disabilities following peripheral nerve blocks, ${ }^{11}$ and the fact that no study has demonstrated that neurostimulation reduces neurological complication rates. ${ }^{12}$

Finally we must emphasize the importance of the local anesthetic used. The onset, duration and level of sensory and motor blocks are all function of the type, volume and concentration of the local anesthetic. More information on different local anesthetics is required since the majority of the published studies concerns lidocaine. ${ }^{2-4}$ What is true for lidocaine may not be relevant for ropivacaine, bupivacaine or L-bupivacaine.

\section{Conclusion}

Our results suggest that the radial nerve should be blocked before the ulnar nerve when blocking the brachial plexus at the humeral canal. The sequence should then become median, radial, ulnar and musculocutaneous nerve. 


\section{References}

1 Dupre LJ. Brachial plexus block through humeral approach (French). Cah Anesthesiol 1994; 42: 767-9.

2 Bouaziz H, Narchi P, Mercier FJ, et al. Comparison between conventional axillary block and a new approach at the midhumeral level. Anesth Analg 1997; 84: 1058-62.

3 Carles M, Pulcini A, Macchi P, Duflos P, RaucoulesAime M, Grimand D. An evaluation of the brachial plexus block at the humeral canal using a neurostimulator (1417 patients): the efficacy, safety, and predictive criteria of failure. Anesth Analg 2001; 92: 194-8.

4 Gaertner E, Kern O, Mahoudeau G, Freys G, Golfetto T, Calon $B$. Block of the brachial plexus branches by the humeral route. A prospective study in 503 ambulatory patients. Proposal of a nerve-blocking sequence. Acta Anaesthesiol Scand 1999; 43: 609-13.

5 Pocock SJ. Methods of randomization. In: Pocock SJ (Ed.). Clinical Trials. A Practical Approach, 10th ed. New York: Wiley; 1991: 67-89.

6 Auroy $\Upsilon$, Benhamou D, Bargues L, et al. Major complications of regional anesthesia in France. The SOS regional anesthesia hotline service. Anesthesiology 2002; 97: 1274-80.

7 Auroy $\Upsilon$, Narchi P, Messiah A, Litt L, Rouvier B, Samii $K$. Serious complications related to regional anesthesia. Results of a prospective survey in France. Anesthesiology 1997; 87: 479-86.

8 Clergue F, Auroy $\Upsilon$, Pequignot F, Jougla E, Lienhart A, Laxenaire MC . French survey of anesthesia in 1996. Anesthesiology 1999; 91: 1509-20.

9 Horlocker TT, Kufner RP, Bishop AT, Maxson PM, Schroeder DR. The risk of persistent paresthesia is not increased with repeated axillary block. Anesth Analg 1999; 88: 382-7.

10 Moore DC, Mulroy MF, Thompson GE. Peripheral nerve damage and regional anaesthesia (Editorial). $\mathrm{Br} \mathrm{J}$ Anaesth 1994; 73: 435-6.

11 Kaufman BR, Nystrom E, Nath S, Foucher G, Nystrom $A$. Debilitating chronic pain syndromes after presumed intraneural injections. Pain 2000; 85: 283-6.

12 Delaunay L. Complications des blocs tronculaires et plexiques. Le praticien en anesthésie réanimation 2001; 5: 267-75. 